\title{
Implementation of European Council Resolution ResAP(2008)1 in Italy. National and Regional Regulation of Tattoo Practices: Diversity and Challenges
}

\author{
Alberto Renzoni ${ }^{\mathrm{a}}$ - Antonia Pirrera ${ }^{\mathrm{a}}$ Francesco Novello $^{\mathrm{a}}$. \\ Maria Simonetta Diamante ${ }^{b} \cdot$ Carmine Guarino $^{a}$ \\ ${ }^{a}$ National Centre ONDICO, Istituto Superiore di Sanità, Rome, and ${ }^{\mathrm{b}}$ Ministry of Economic Development, \\ Rome, Italy
}

\begin{abstract}
In Italy, tattoos and permanent make-up have become increasingly popular in recent years. The number of tattoo parlours has increased from 257 in 2009 to 2,055 in 2014, wich is a eight-fold increase over the last 6 years. Although there is no specific legislation, the Italian Ministry of Health issued a document containing the 'Guidelines for the implementation of procedures for tattooing and piercing in safe conditions'. This document has not been adopted by all Italian regions, principally regarding training course requirements for tattoo professionals, creating a highly fragmented situation that resembles the European scene in miniature. ResAP(2008)1, which is not mandatory in Italy but was made binding by Italian Decree n. 206/2005, has been applied uniformly throughout the country. Thus, as far as the safety of inks is concerned, the surveillance system appears to be working well. However, surveillance has highlighted the presence of non-compliant inks and potentially unsafe preparations for tattoo removal in the market. Updating and rebalancing the situation will be the goal in order to face the challenge of combining well-being with the on-going
\end{abstract}

social demand of looking after and beautifying the body. This would include the growing fashion of tattoos, provided that the products that are used are safe and that tattooing is performed in controlled hygienic conditions that fully guarantee the health of consumers.

(c) 2015 S. Karger AG, Basel

Compared with the significant growth of the practice of tattooing in Italy, related legislation has not succeeded in keeping up with its development. This situation is common to many European countries and, in most cases, 'strongly suggested directives' or 'Guidelines' rather than specific regulations have been issued.

The National Centre Organismo Notificato Dispositivi Medici e Cosmetici of the Istituto Superiore di Sanità has, inter alia, the task of making assessments to form the basis of regulatory proposals in areas relevant to public health where there is no specific regulation. The situation regarding tattooing and piercing is a case in point. 
At the moment, there are no official data describing the percentage of tattooed individuals in the general population or in specific age groups. Some partial data show that about $20 \%$ of adults were tattooed as of 2012 [1] and that the percentage of teenagers (12-18 years of age) with at least one tattoo had increased from 6.6 to $7.5 \%$ in the years 2002-2011 [2]. Circumstantial evidence of the growth of tattooing is seen in the number of operating tattoo parlours, which has increased from 257 in 2009 to 2,055 in 2014, which is a eight-fold increase over the last 6 years [3]. Some information regarding awareness, attitudes and the practice of tattooing among the population, although fragmentary, is available in the following scientific publications.

In 2005, a study on a sample of 577 students aged between 14 and 20 years was published to describe the educational initiative involving schools in the Region of Tuscany. This study reported that $4.8 \%$ of students had at least one tattoo. A definite increase in frequency of having a tattoo with age was evident among females, but this same frequency could not be detected among males, owing to the low numbers (not significant) in the study. Approximately $95.2 \%$ of those questioned were aware of the fact that piercing and tattooing might carry health risks. Of these, 95.2\% indicated the possible risk of infections, $21.0 \%$ indicated the risk of allergic reactions, and $9.0 \%$ indicated the risk of aesthetic damage [4]. It is worth noting that specific regional regulations have been in place in Tuscany since 2004; indeed, Tuscany was the first region to issue specific regional laws. This example leads us to believe that good results regarding the awareness of risks from tattooing and their minimisation can be obtained when the sector is regulated by laws and when a good level of training is required.

In 2010, a study on the prevalence, knowledge and practices of and attitudes towards body art was published. These data, derived from a survey conducted at the University of Palermo, showed that $31.7 \%$ of a sample of 1,200 undergraduate university students had at least one tattoo. In general, students from a scientific background showed a higher rate of interest in body art (42.9\%) compared with students from the humanities (19.5\%). The results of the study supported the conclusion that cultural choice and lifestyle as well as gender (in the humanities and scientific groups, respectively, 31.8 and $47.6 \%$ of males had a tattoo, which was significantly more than females, at 14.3 and $26.9 \%$, respectively) were associated with body art. However, there seemed to be no association with physical characteristics such as age, height, or weight. Students in the sample seemed to be clear as to why someone might desire to have a tattoo. On the contrary, the individuals who were questioned had no accurate idea of the consequences of getting a tattoo to their health or body, apart from the general risk of infection [5].

A 2010 study conducted in Northeast Italy evaluated the awareness of health-related risks in a sample of 4,277 secondary school students aged 14-22 years; $6 \%$ had a tattoo. Males appeared to be consistently less conscious of the risks of infectious diseases and mandatory hygienic norms when obtaining body art and were less likely to choose a certified parlour to obtain body art or to seek medical advice in the event of related medical complications. In contrast, high school-aged students had a better knowledge of the risks of infectious diseases related to body modifications, were more likely to use certified body art parlours and knew the hygienic norms expected in such salons [6].

In 2012, a study was published to verify the practices and knowledge of the risks related to body art among university freshmen in Bari and Naples, both cities in Southern Italy. Of a sample of 3,868 people selected from 26 degree courses, $597(19.8 \%)$ were tattooed. The mean age when the first tattoo was obtained was 17 years. Of the respondents, $84.4 \%$ claimed to know the infectious risks associated with body art practices, but only $4.1 \%$ correctly identified the infectious 
diseases that could be transmitted through these procedures. While $59.2 \%$ of the sample declared that non-infectious diseases could occur after a tattoo or a piercing, only $5.4 \%$ of them correctly identified allergies, cysts, bleeding and scars. Of the sample, 23.4\% reported complications [7].

The Italian Ministry of Health first addressed the problem of tattooing in 1998, when it issued document no. 2.9/156 'Guidelines for the implementation of procedures for tattooing and piercing in safe conditions' [8] and the subsequent interpretive letter no. 2.8/633 of the same year [9]. These documents focused on the risk of infection caused by blood-borne pathogens, of skin infections, of toxic effects due to substances used for pigmentation of the dermis as well as of the measures that should be applied, in particular, the basic rules for hygiene and environmental control. The Ministry requirements for a professional tattooist are as follows: at least 18 years of age and in possession of a certificate of participation in a training course for tattoo artists. In 1998, health hazards related to tattoo practice had limited impact at the national level and were consequently underestimated. Therefore, the public health departments of the Italian regions were allowed to adopt the guidelines with modifications and the consequent promulgation of regional directives and/or other legislative measures. Most of the regions simply enforced the Ministry guidelines, a few issued more stringent rules, and others had no regulations at all (see table 1). From the table, it is evident that the regulatory fragmentation is also reflected in the length of the required training courses; the qualifications of tattoo artists are extremely varied at the regional level, and the courses range from $14 \mathrm{~h}$ to $600 \mathrm{~h}$. Some regions require 10 years of compulsory schooling as a threshold level of education. The great variability of the duration of the training courses poses serious issues. Differences in the authorisation processes for establishing a tattooing business mean that there is a lack of equivalence and that the level of health
Table 1. Status of tattoo regulation in the Italian regions

\begin{tabular}{llc}
\hline Regions & $\begin{array}{l}\text { Regional } \\
\text { regulation }\end{array}$ & $\begin{array}{l}\text { Training courses for } \\
\text { tattoo artists/hours } \\
\text { (minimum) }\end{array}$ \\
\hline Abruzzo & no & - \\
Basilicata & no & - \\
Calabria & yes & 90 (planned) \\
Campania & yes & 50 \\
Emilia-Romagna & yes & 14 \\
Friuli-Venezia & awaiting & - \\
$\quad$ Giulia & approval & \\
Lazio & yes & 90 \\
Liguria & yes & 30 \\
Lombardia & yes & 90 \\
Marche & awaiting & - \\
& approval & \\
Molise & no & - \\
Piemonte & yes & awaiting approval \\
Puglia & yes & 90 \\
Sardegna & yes & 60 \\
Sicilia & yes & 90 \\
Toscana & yes & 600 \\
Trentino & yes & 60 \\
Alto Adige & yes & 30 \\
Umbria & yes & $90+$ public register \\
Valle d'Aosta & no & - \\
Veneto & yes & 90 \\
\hline & & \\
\hline
\end{tabular}

protection varies across the different regions. Clearly, the recognition status of a tattoo artist varies from one region to another, and there is the additional problem of the recognition of qualifications of tattoo artists from foreign countries. Consistent criteria are essential for the definition of a uniform professional profile for tattooists that will ensure a minimum technical level of skill to protect consumers and to allow comparison and competition on equal terms for market access.

The responsibility for issuing authorisation to establish a tattooing enterprise and for the routine monitoring of licensed tattoo parlours rests with Aziende Sanitarie Locali (Local Health Units). These units operate within the National Health Service; however, even in this case, there is considerable variation in the licensing re- 
quirements and monitoring frequency. In this context, on a small scale, Italy reflects the EU situation.

The 'Resolution ResAP(2008)1 on requirements and criteria for the safety of tattoos and permanent make-up', hereafter referred to as ResAP, is not mandatory in Italy. Nevertheless, the Italian Decree n. 206/2005 [10], based on the 'EU General Product Safety Directive (GPSD) 2001/95/CE', confers a binding nature on ResAP; indeed, art. 105 of the Decree states that '...in the absence of law, product safety is assessed on the basis of voluntary national standards transposing European standards ..., European Commission recommendations..., or referral to codes of good practices relating to safety in the sector concerned, to the latest technology, to the level of safety which consumers may reasonably expect'. Accordingly, tattoo inks must comply with ResAP before being marketed; otherwise, the national authority can ban their importation/sale. The national authority can also order the seizure of unsafe tattoo products. A substantial consequence is the immediate notification to all $\mathrm{EU}$ Countries through the RAPEX system. So, in Italy, ResAP is applied uniformly throughout the country and, as far as the safety of inks is concerned, the surveillance system, which is coordinated by the Ministry of Health, together with the Regional Agencies for the Protection of the Environment, Local Health Units, Carabinieri Healthcare Command (Carabinieri NAS). Office of Maritime, Air and Border Health (Uffici di Sanità Marittima, Aerea e di Frontiera) and Istituto Superiore di Sanità, appears to be working well. Based on the results of analyses of inks that were undertaken after either RAPEX warnings or individual complaints or as part of routine controls following sampling campaigns, approximately $40 \%$ of samples that were investigated were found to be non-compliant with ResAP requirements. Such campaigns revealed the presence in the market of fake inks of unknown composition that mimicked brands of inks that com- plied with ResAP requirements; the results of this surveillance are published on the website of the Ministry of Health. This raises the problem of traceability and product control, an issue that should be addressed at the EU level.

Other issues waiting to be addressed are the harmonisation of methods for analysing inks and the safety of products for tattoo removal. The compliance of inks to the ResAP is assessed by methods that may differ in the preparation and/ or subsequent analysis. Official Italian laboratories, which perform the control analysis upon request by the Ministry of Health, adopt more restrictive methods because they are inspired by the precautionary principle. Methods used in other EU states provide different results. The risk related to the substances used for tattoo removal represents another emerging problem. Whereas ResAP has addressed the safety of the substances contained in tattoo ink, there has been no provision for the substances used for their removal. A variety of special preparations are commercially available. These preparations are applied on or beneath the skin and are not listed as cosmetics, medical devices or drugs. Evidence is piling up about the adverse effects of such substances and, once again, they need to be regulated.

An area of tattoo practice worthy of study and regulation is that performed for medical purposes, e.g. reconstruction of the nipple-areola complex after mastectomy, camouflage of scars, and endoscopic tattoos for gastrointestinal investigations. These medical tattoos require special procedures that must comply with the fundamental rules of sterility and are very similar to those used for surgical operations. Some medical tattoos are included in the list of medical devices of the Italian National Classification of Medical Devices, according to Directive 93/42/EEC of June 14, 1993.

Awaiting European legislation, the next step will be the proposal for an update of the 1998 'Guidelines' of the Ministry of Health to include relevant scientific and technological evolutions 
and to standardise the training of tattooists. Some final, but not less important, objectives include the following:

- The creation of an Italian network for the reporting of complications and adverse events related to tattoos (database included), with the collaboration of first aid locations and health care facilities as well as of general practitioners and dermatologists.

- Obtaining more reliable data to know the exact size of the tattooed population, in general and by age groups as well as sex, including gathering further detailed information on the knowledge and awareness of and on the attitudes towards the risks of tattooing.

- Institution of a national register of certified tattoo artists on the basis of standardised training courses all over the country, which would supersede the fragmentary regional requirements, would impose a well-defined profile for tattooists and would ensure a technical level of skill by the tattooists to protect consumers.
- Institution of a register of ink and tattoo equipment manufacturers to overcome the problem of traceability.

The final goal of the Italian Health Authority aligns perfectly with the statements made at the meeting of the European Commission SANCO B3, Consumer Safety Network, Subgroup Tattoos of June 23rd, 2014: ' . ..creation of a European system of registration or recognition of tattooists, a tattoo vigilance system where undesirable effects could be registered and be available to all Member States and information campaigns to increase awareness of consumers of the risks of receiving tattoos, in particular by unqualified tattooists'. In conclusion, one of the challenges that awaits us deals with a lifestyles in which well-being is coupled with a growing social demand for looking after and beautifying the body. This also includes the growing fashion of tattoos, provided that the products that are used are safe and that the tattooing is performed in controlled, hygienic conditions that fully guarantee the health of the consumers.

\section{References}

1 SWG Trieste: Sondaggio online dal titolo: I tatuaggi. 2012. www.agcom.it (accessed August 3, 2012).

2 EURISPES: Indagine Conoscitiva sulla Condizione dell'Infanzia e dell'Adolescenza in Italia 2011.

3 Unioncamere-Infocamere: Registro delle Imprese 2014.

4 Boncompagni G, Lazzeri G, Martiello MA, Incandela L, Santori R, Spinelli GM, Senatore R, Gentili G, Giacchi M, Pozzi T: Related risks of tattooing and body piercing: prevalence study in a convenience sample. J Prev Med Hyg 2005;46:153-158.
5 Sidoti E, Paolini G, Tringali G: Prevalence, knowledge, attitudes and practices towards body art in university students: body art as an indicator of risk taking behaviours? Ital J Public Health 2010;7:386-394.

6 Cegolon L, Miatto E, Bortolotto M, Benetton M, Mazzoleni F, Mastrangelo G, VAHP Working Group: Body piercing and tattoo: awareness of health related risks among 4,277 Italian secondary school adolescents. BMC Public Health 2010;10:73-81.
7 Gallè F, Quaranta A, Napoli C, Di Onofrio V, Alfano V, Montagna MT, Liguori G: Body art and health risks: young adults' knowledge in two regions of southern Italy. Ann Ig 2012;24:535-542.

8 Ministero della Sanità: Linee Guida del Ministero della Sanità per l'Esecuzione di Procedure di Tatuaggio e Piercing in Condizioni di Sicurezza. Circolare 5 Febbraio 1998 n. 2.9/156.

9 Ministero della Sanità: Chiarimenti Forniti dal Consiglio Superiore della Sanità. Circolare 16 Luglio 1998 n. 2.8/633.

10 Decreto Legislativo del 6 Settembre 2005 no. 206 'Codice del Consumo'.

Dr. Antonia Pirrera

ONDICO, Istituto Superiore di Sanità

Viale Regina Elena, 299

IT-00161 Rome (Italy)

E-Mail antonia.pirrera@iss.it 